\title{
Genetic engineering of the glucocorticoid receptor by fusion with the herpes viral protein VP22 causes selective loss of transactivation
}

\author{
J Soden, A Stevens and D W Ray \\ Clinical Research Division II, Endocrine Sciences Research Group, Faculty of Medicine, Stopford Building, University of Manchester, Manchester M13 9PT, UK \\ (Requests for offprints should be addressed to D W Ray, Room 3.903, Stopford Building, University of Manchester, Manchester M13 9PT, UK; \\ Email: David.W.Ray@man.ac.uk)
}

\begin{abstract}
The development of methods for engineering proteins with novel properties opens the way to manipulating intracellular processes in a therapeutically useful way. Glucocorticoids, acting via glucocorticoid receptors (GR), are potent anti-inflammatory agents, acting to oppose nuclear factor kappa B (NFKB) function. The herpes viral protein, VP22, has been reported to confer intercellular trafficking activity on 'cargo' proteins, potentially facilitating gene therapy with intracellular proteins.

VP22GR, resulting from the addition of VP22 to the N terminal of GR, was equipotent with the wild-type GR in opposing NFKB p65-driven expression of an NFKB reporter gene. Surprisingly, VP22GR was incapable of
\end{abstract}

inducing transactivation of positive glucocorticoid reporter genes (MMTV-luc and TAT3-luc). Furthermore, the VP22GR had powerful dominant negative activity on both endogenous and exogenous GR transactivation. VP22GR was cytoplasmic in quiescent cells, and after hormone addition underwent nuclear translocation to share the same distribution as the GR. The ability of the VP22GR to selectively confer and enhance glucocorticoid-dependent transrepression of NFKB may be of use therapeutically in e.g. transplant rejection, inflammatory arthritis or asthma.

Journal of Endocrinology (2002) 172, 615-625

\section{Introduction}

Glucocorticoid effects on transcription may be mediated by the direct binding of activated glucocorticoid receptors (GR) to target DNA, homodimerisation and recruitment of co-activators and also by GR interfering with other transcription factor function, including AP-1, nuclear factor kappa B (NFkB) and NUR77 (Jonat et al. 1990, Miner \& Yamamoto 1991, Schule \& Evans 1991, Konig et al. 1992, Heck et al. 1994, Ray \& Prefontaine 1994, Caldenhoven et al. 1995, Scheinman et al. 1995a,b, Wade et al. 1995, Horwitz et al. 1996). The proinflammatory actions of NFKB are well characterised, and opposition of NFKB by GR can explain many of the anti-inflammatory actions of glucocorticoids (Scheinman et al. 1995b, Cato \& Wade 1996, Nissen \& Yamamoto 2000). Glucocorticoid sensitivity is related to GR expression (Vanderbilt et al. 1987) and, furthermore, opposition of NFKB action, and so anti-inflammatory activity, can be enhanced by overexpressing the GR (Mathieu et al. 1999).

The GR has a defined domain structure which comprises an $N$ terminal transactivation domain (AF-1), a central DNA binding domain (DBD) which is the most highly conserved structure with other members of the steroid hormone receptor family, and a C terminal ligand binding domain (LBD), which also includes a second activation domain, a hinge region, and sites for interaction with heat shock proteins (Hollenberg \& Evans 1988). The $\mathrm{N}$ terminal transactivation domain extends from amino acid 77 to 262, but a core domain from 187 to 244 contributes most of this activity (Warnmark et al. 2000). The $\mathrm{C}$ terminal transactivation domain depends on ligandinduced folding to recruit co-activator proteins, including members of the p160 family, GRIP1 and SRC1 (Hong et al. 1997, Collingwood et al. 1999, McKenna et al. 1999). GR inhibition of NFKB is mediated by interaction with the RelA (p65) component (Scheinman et al. 1995b). The GR DBD binds to RelA when it is bound to DNA, and the GR LBD represses the RelA transactivation domain (Nissen \& Yamamoto 2000).

VP22 is a $38 \mathrm{kDa}$ structural protein from the herpes simplex virus (HSV) and has the property of intercellular transport (Elliott \& O'Hare 1997). VP22 trafficking appears to involve contacts with the actin architecture of the cell, and does not require the Golgi apparatus (Elliott \& O'Hare 1997). It has been shown that 'cargo' proteins may be fused with the VP22 to allow them intercellular trafficking potential (Elliott \& O'Hare 1999). Such 'trafficked' proteins appear to retain function, as in the case of HSV thymidine kinase, and p53 (Koelle et al. 1998, Phelan et al. 1998). An additional property of both VP22 alone and its fusion proteins appears to be its intracellular distribution. 
In unstimulated cells the GR is sequestered in the cytoplasm, and removal of its $\mathrm{C}$ terminal, ligand binding domain generates a nuclear resident, constitutive transcriptional activator (Hollenberg \& Evans 1988). As VP22 targets cargo proteins to the nucleus of transfected cells (Fang et al. 1998), or the cytoplasm of synthesising cells and the nucleus of protein recipient cells (Elliott \& O'Hare 1999), by imposing additional controls on its intracellular localisation, it may alter GR function. In addition, it may be possible to influence tissue glucocorticoid sensitivity by allowing intercellular movement of GR.

This work describes the generation and analysis of a VP22-GR fusion protein with extreme dissociation of RelA transrepression from transactivation. Such proteins may have utility in dissecting the role of the two pathways for functional effects in vitro, and also for development as gene therapy for inflammatory disease.

\section{Materials and Methods}

\section{Construction of plasmids}

The human GR cDNA was amplified using two primers: $\mathrm{N}$ terminal 5' CTG CGT CTT CAC CCT CAC TGG C and $\mathrm{C}$ terminal $5^{\prime}$ TCA CTT TTG ATG AAA CAG AAG TTT TTT $G$ and was cloned directly into the pVP22/myc-his TOPO vector (Invitrogen, Paisley, UK). This includes the full-length VP22 coding region to codon 301. This resulted in an in-frame fusion of the $3^{\prime}$ terminal of the VP22 coding region with codon 42 (serine) of the human GR, VP22GR. The construct was fully sequenced to confirm freedom from PCR introduced errors.

The VP22 GRmyc was generated using the same 5' primer but with the $3^{\prime}$ primer lacking the endogenous translation stop codon to enable translation to continue across the myc epitope. The $\mathrm{C}$ terminal primer sequence was: 5' CTT TTG ATG AAA CAG AAG TTT TTT GAT A. Again, the construct was fully sequenced.

VP22 GRdim (dimerisation deficient) was generated from VP22GR by excising a cassette with BsmB1 and Cla1 and replacing it with the cassette from pSGGR(A458T) (a kind gift of Dr P Herrlich, Institute for Toxicology and Genetics, Karlsruhe, Germany) (Heck et al. 1997, Reichardt et al. 1998). The 3' terminal of VP22GR was disrupted by excising a cassette from GR nucleotides 1536 to 1921 with BstB1, and religating it to make VP22GR(-LBD). All recombinant plasmids were sequenced.

The GFPGR consists of the full-length murine GR cDNA with a $5^{\prime}$ fusion to the green fluorescent protein (GFP) cDNA, the kind gift of Dr Paul Housley, University of South Carolina (Galigniana et al. 1998).

The TAT3-luc reporter, consisting of three copies of the glucocorticoid response element (GRE) from the tyrosine aminotransferase gene upstream of a minimal promoter linked to luciferase, was the gift of Prof. K
Yamamoto (Iniguez et al. 1997). The MMTV-luc plasmid consisted of $1.5 \mathrm{~kb}$ of the mouse mammary tumour virus long terminal repeat fused to the firefly luciferase gene in the pXP-2 backbone (Ray et al. 1996a). The full-length wild-type human GR expression vector (wtGR) had the human GR cDNA inserted into the pcDNA3 plasmid (Ray et al. 1999). The full-length rat GR expression vector, p6RGR, consisted of the rat GR cDNA driven by the Rous sarcoma virus (RSV) promoter. p6RGRN525 lacked the $\mathrm{C}$ terminal ligand binding domain by deletion from amino acid 525. p6RGR 407C lacked the $\mathrm{N}$ terminal up to amino acid 407. All three rat constructs were the kind gifts of Dr Jorge Iniguez-Lluhi and Professor Keith Yamamoto, University of California at San Francisco, USA (UCSF) (Godowski et al. 1988). The estrogen receptor expression vector (cytomegalovirus-estrogen receptor; CMV-ER) contained the full-length human $\mathrm{ER} \alpha$ in the pcDNA3 vector, and was the kind gift of Dr Maurice Needham, AstraZeneca, UK. The mineralocorticoid receptor (MR) expression vector (CMV-MR) contained the human MR cDNA inserted into pcDNA3, and was the kind gift of Dr Maurice Needham. The estrogen reporter gene (ERE-luc) consisted of three copies of a consensus estrogen response element (ERE) upstream of a minimal tk promoter and the firefly luciferase gene (luc), and was the kind gift of Dr Maurice Needham. A CMV- $\beta$ Gal plasmid was used to control for differences in transfection efficiency, as previously described (Ray et al. 1999).

\section{Cell culture and transfection}

COS 7, HeLa and A549 cells were obtained from ECACC (Salisbury, UK), and were cultured as previously described (Ray et al. 1999) in DMEM with glutamax (Gibco, Paisley, Strathclyde, UK) supplemented with 10\% fetal calf serum. No antibiotics were used. Cells were transfected using Lipofectamine Plus (Life Technologies, Paisley, Strathclyde, UK) and were divided into treatment and control groups so that within each experiment all the groups were from a single transfection. Typically, $5 \times 10^{5}$ cells were transfected in a $10-\mathrm{cm}$ tissue culture dish. All experiments were performed on at least three separate occasions. Cells were routinely co-transfected with a CMV$\beta G a l$ plasmid, and the results were expressed as corrected light units by dividing the luciferase assay light units by the optical density 570 from the $\beta \mathrm{Gal}$ assay using $\mathrm{CPRG}$ as substrate as previously described (Ray et al. 1999).

Cells were transfected with $3 \mu \mathrm{g}$ MMTV-luc, or $3 \mu \mathrm{g}$ TAT3-luc reporter plasmids, and combinations of $1 \mu \mathrm{g}$ pcDNA3 GR $\alpha, 1 \mu \mathrm{g}$ p6 RGR, $1 \mu \mathrm{g}$ p6 RGRN525, $1 \mu \mathrm{g}$ p6 RGR407C. The total amount of input DNA was kept constant by using either the pcDNA3 (to control experiments using the pcDNA3 vector), or the pVP22 (to control experiments using the VP22 vector) empty vectors. All experiments had $1 \mu \mathrm{g}$ CMV- $\beta$ Gal added. 
The human T lymphoblast cell line, CEM C7A, was obtained from Dr G Brady, University of Manchester, UK, and cells were cultured in Optimem plus glutamax (Gibco) supplemented with 5\% fetal calf serum. Cells were suspended at $10^{7}$ cells per $\mathrm{ml}$, and $0.8 \mathrm{ml}$ was added to a 4-mm pathlength electroporation cuvette (BioRad, Hercules, CA, USA). DNA was added, and the cells were electroporated at $260 \mathrm{~V}$ and $1050 \mu \mathrm{F}$ in an 'Easyject1' electroporator (Eurogentec, Seraing, Belgium). TAT3-luc $(10 \mu \mathrm{g}), \mathrm{CMV}-\beta \mathrm{Gal}(1 \mu \mathrm{g})$ and either VP22 or VP22GR $(5 \mu \mathrm{g})$ were used.

\section{Immunocytochemistry}

Cells were transfected with $2 \cdot 5 \mu \mathrm{g}$ expression vector in $10-\mathrm{cm}$ tissue culture dishes and then plated onto multichamber slides for immunoperoxidase detection, or onto sterilised glass cover slips for immunofluorescence.

Immunoperoxidase Cells were fixed in 100\% methanol at $-20{ }^{\circ} \mathrm{C}$ for $20 \mathrm{~min}$. The $\mathrm{C}$ terminal anti-GR antibody P20 (Santa Cruz Biotech, Santa Cruz, CA, USA) was used at 1:100 dilution in PBS $+1.5 \%$ blocking serum, and the immunoperoxidase detection used the Vectastain kit (Vector Laboratories, Burlingame, CA, USA) according to the manufacturer's suggestion. The monoclonal anti-myc antibody was purchased from Sigma (Poole, Dorset, UK), and was used at 1:500 dilution. Again detection was with the Vectastain kit.

Immunofluorescence Cells were plated onto glass cover slips and fixed in methanol. Cells were incubated with anti-myc $1: 750$ in PBS/0.2\% BSA/4\% goat serum, then goat anti-mouse conjugated to Texas Red 1:1000. Cover slips were mounted in 90\% glycerol/10\% PBS, and sealed with nail varnish.

\section{Immunoblotting}

Whole cell lysates were prepared using a non-ionic lysis buffer consisting of $1 \%$ Triton X-100, $150 \mathrm{mM} \mathrm{NaCl}$, $10 \mathrm{mM}$ Tris ( $\mathrm{pH} 7 \cdot 4), 1 \mathrm{mM}$ EDTA, $0.2 \mathrm{mM}$ sodium vanadate, $0 \cdot 2 \mathrm{mM}$ phenylmethylsulphuryl fluoride, $0 \cdot 5 \%$ NP40. Protein concentration was estimated using the BioRad assay according to the manufacturer's protocol with BSA as the standard. Twenty micrograms protein were resolved on a $7 \cdot 5 \%$ SDS-PAGE gel and transferred to a PVDF (Millipore P, Millipore, Watford, UK) membrane overnight. The membrane was blocked with 5\% non-fat dry milk and probed with anti-myc at 1:1000 dilution in blocking buffer. The membrane was washed in Trisbuffered saline with $0 \cdot 1 \%$ Tween 20 , and the secondary antibody, anti mouse-hrp (Amersham) used at 1:2000 dilution in blocking buffer. Detection was by enhanced
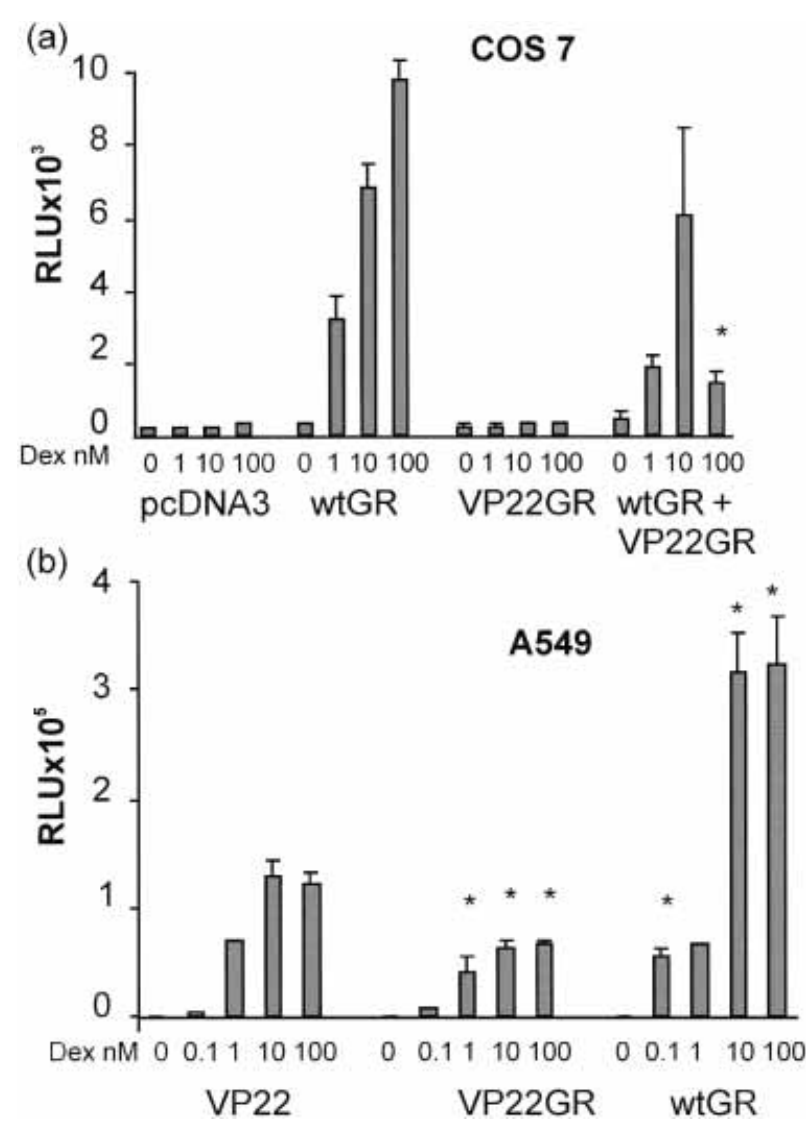

Figure 1 VP22GR is a dominant negative inhibitor of GR-mediated transactivation. (a) COS 7 cells were co-transfected with $3 \mu \mathrm{g}$ MMTV-luc and $1 \mu \mathrm{g} C M V-\beta G a l$ and with $2 \mu \mathrm{g}$ empty vector (pcDNA3), $1 \mu \mathrm{g}$ wild-type GR expression vector (wtGR) or $1 \mu \mathrm{g}$ VP22GR expression vector (VP22GR) with $1 \mu \mathrm{g}$ empty vector, or with $1 \mu \mathrm{g}$ wtGR and $1 \mu \mathrm{g}$ VP22GR. Cells were divided into triplicates after transfection and treated with the indicated concentrations of dexamethasone (Dex) for $16 \mathrm{~h}$ before harvest. Results are expressed as mean corrected relative light units (RLU), the error bars indicate standard deviation. Statistical comparison was made between the wtGR, and wtGR + VP22GR transfectants. ${ }^{*} P<0.05$ compared with wtGR transfected cells treated with the same concentration of dexamethasone. There was no significant difference between VP22GR and empty vector transfected cells. (b) A549 cells were co-transfected with $3 \mu \mathrm{g}$ MMTV-luc and $1 \mu \mathrm{g}$ CMV- $\beta$ Gal, and with $1 \mu \mathrm{g}$ empty VP22 expression vector (VP22) or $1 \mu \mathrm{g}$ VP22GR expression vector (VP22GR). Cells were divided, treated and harvested as described above. Results are expressed as mean corrected relative light units (RLU) and standard deviation. ${ }^{*} P<0.05$ compared with the VP22 transfected cell at the same concentration of ligand. The results are from a representative experiment performed in triplicate and the experiment was repeated on six occasions.

chemiluminescence (ECL) as previously described (Ray et al. 1996b).

\section{Statistics}

Comparisons were made using analysis of variance. 


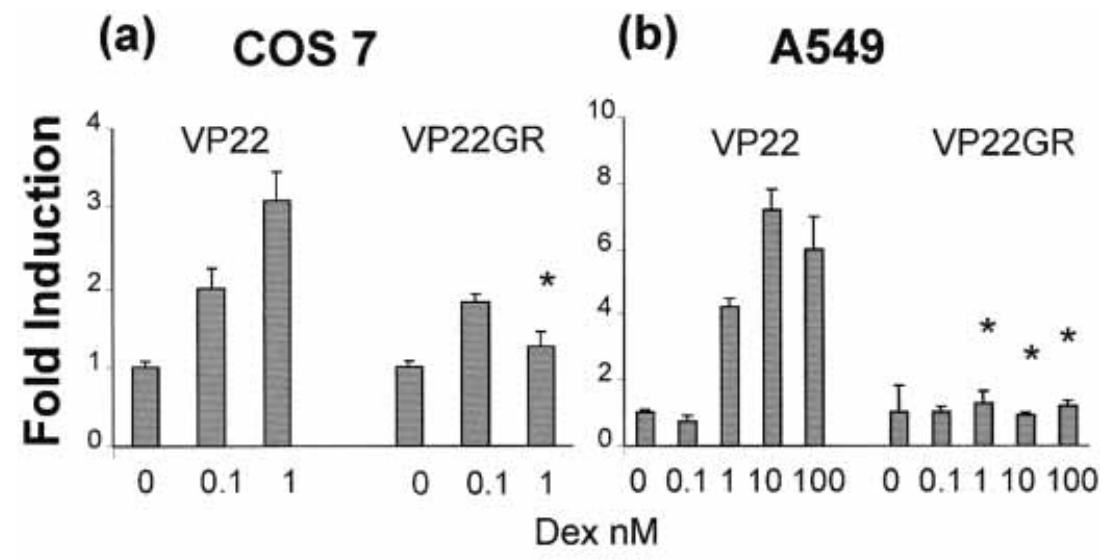

$\begin{array}{ll}\text { (c) CEM C7A } & \text { (d) HeLa }\end{array}$

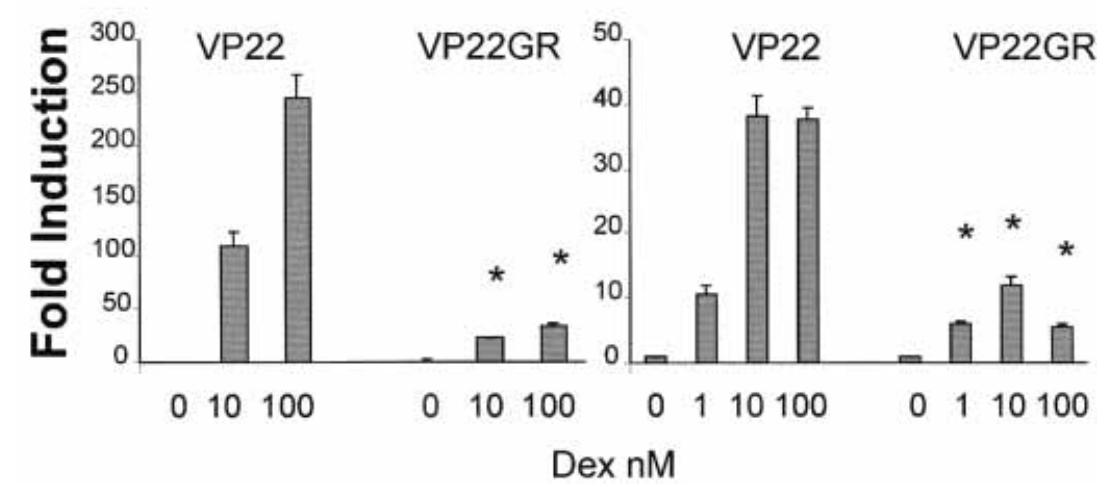

Figure 2 VP22GR has dominant negative activity on both endogenous and exogenous GR. (a) COS 7 cells were co-transfected with $3 \mu \mathrm{g}$ TAT3-luc, $1 \mu \mathrm{g}$ CMV- $\beta$ Gal, $1 \mu \mathrm{g}$ wtGR and with either $1 \mu \mathrm{g}$ VP22, or $1 \mu \mathrm{g}$ VP22GR. (b) A549 cells were transfected with $3 \mu \mathrm{g}$ TAT3-luc, $1 \mu \mathrm{g}$ CMV- $\beta$ Gal, and either $1 \mu \mathrm{g}$ VP22, or $1 \mu \mathrm{g}$ VP22GR. (c) CEM C7A cells were transfected with $10 \mu \mathrm{g}$ TAT3-luc, $1 \mu \mathrm{g} C M V-\beta G a l$ and with either $5 \mu \mathrm{g}$ VP22 or $5 \mu \mathrm{g}$ VP22GR. (d) HeLa cells were transfected with $3 \mu \mathrm{g}$ TAT3-luc, $1 \mu \mathrm{g}$ CMV- $\beta$ Gal, and with either $1 \mu \mathrm{g}$ VP22, or $1 \mu \mathrm{g}$ VP22GR. Cells were divided, treated and harvested as described. Results are expressed as mean fold induction of corrected relative light units \pm standard deviation. ${ }^{*} P<0.05$ compared with VP22 transfected cells at the same concentration of ligand. A representative experiment performed in triplicate and repeated on at least four occasions. Dex, dexamethasone.

\section{Results}

VP22GR has dominant negative activity

The VP22GR did not activate the MMTV-luc reporter in COS 7 cells (Fig. 1a), but did inhibit wild-type GR function at high concentrations of dexamethasone (Fig. 1a). Expression of VP22GR significantly inhibited MMTV-luc induction in the human pulmonary epithelial cell line A549, which contains endogenous GR, at concentrations of dexamethasone greater than $0 \cdot 1 \mathrm{nM}$ (Fig. 1b). In contrast, expression of the full-length, wildtype GR increased glucocorticoid sensitivity (Fig. 1b).
Transfection of the empty VP22 vector did not alter the dexamethasone induction of reporter gene activity.

These experiments were repeated using a less complex glucocorticoid reporter gene, TAT3-luc. VP22GR did not allow dexamethasone induction of the reporter gene in COS 7 cells, in contrast to wild-type GR (data not shown). We found that concentrations of dexamethasone greater than $1 \mathrm{nM}$ caused activation of the TAT3-luc reporter in COS 7 cells in the absence of exogenous GR, probably due to low-level expression of endogenous GR (data not shown). Therefore, dexamethasone 
(a)

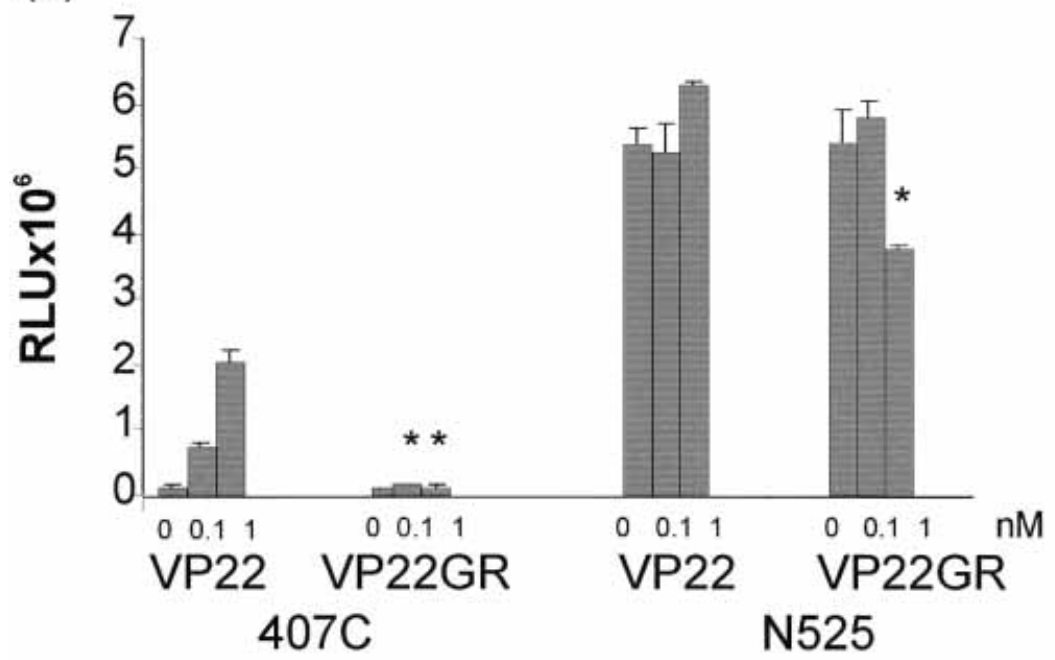

(b)

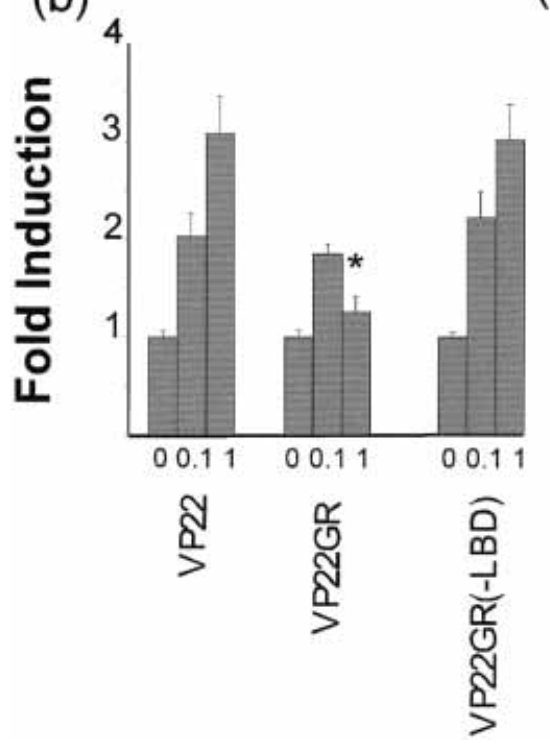

(c)

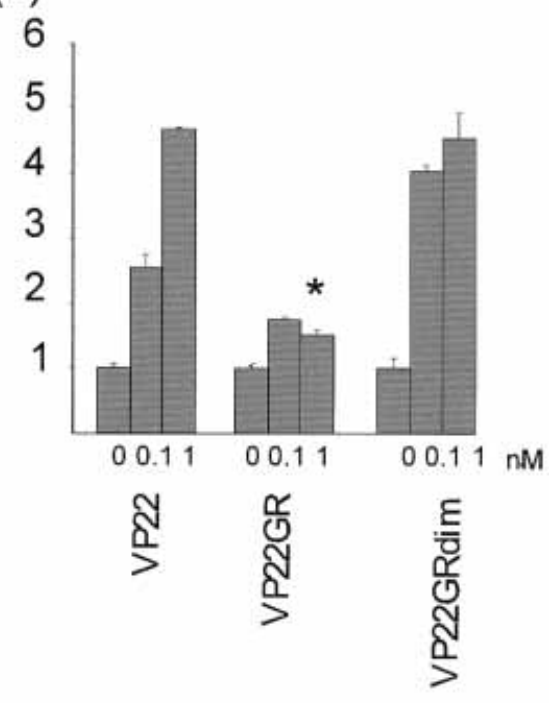

Figure 3 VP22GR inhibits both $\mathrm{N}$ and $\mathrm{C}$ terminal activation domains of the GR, and requires intact dimerisation and ligand binding functions. (a) COS 7 cells were transfected with $3 \mu \mathrm{g}$ TAT3-luc, $1 \mu \mathrm{g}$ CMV- $\beta$ Gal, and with either $1 \mu \mathrm{g}$ RGR407C (407C) or RGRN525 (N525), and with either $1 \mu \mathrm{g}$ VP22 (VP22) or VP22GR (VP22GR). Cells were treated overnight with the indicated concentrations of dexamethasone before harvest and analysis. Results are expressed as correcected relative light units (RLU), means \pm standard deviation. ${ }^{\star} P<0.05$ compared with the VP22 transfected control at the same concentration of ligand. A representaive experiment, performed in triplicate, and repeated on three occasions.

(b) COS 7 cells were transfected with $3 \mu \mathrm{g}$ TAT3-luc, $1 \mu \mathrm{g}$ CMV- $\beta \mathrm{Gal}, 1 \mu \mathrm{g}$ wtGR, and with $1 \mu \mathrm{g}$ VP22, $1 \mu \mathrm{g} \mathrm{VP22GR,} \mathrm{or} 1 \mu \mathrm{g}$ VP22GR(-LBD). (c) COS 7 cells were transfected with $3 \mu \mathrm{g}$ TAT3-luc, $1 \mu \mathrm{g}$ CMV- $\beta$ Gal, $1 \mu \mathrm{g}$ wtGR, and with $1 \mu \mathrm{g}$ VP22, $1 \mu \mathrm{g}$ VP22GR, or $1 \mu \mathrm{g}$ VP22 GRdim. Cells were treated for $16 \mathrm{~h}$ with dexamethasone, and harvested as described. Results are expressed as fold induction of the corrected RLU \pm standard deviation. ${ }^{*} P<0 \cdot 05$ compared with the VP22 transfected control treated at the same concentration of dexamethasone. A representative experiment performed in triplicate and repeated five times. 
concentrations were restricted to $1 \mathrm{nM}$ in COS 7 cells transfected with the TAT3-luc reporter.

VP22GR showed dominant negative activity on wildtype GR in COS 7 cells (Fig. 2a). This effect was also seen using the TAT3-luc reporter in three human cell lines which express endogenous GR: A549, CEM C7A and HeLa cells (Fig. 2b,c,d). Dexamethasone at less than $10 \mathrm{nM}$ did not activate TAT3-luc in CEM C7A cells.

\section{VP22GR and GR interactions: structural requirements}

VP22GR inhibited GR transactivation, and so GR molecules with either the $\mathrm{N}$ terminal AF-1 deleted (RGR407C), or the $\mathrm{C}$ terminal ligand binding domain and AF-2 deleted (RGRN525) were also examined. Both these deleted constructs are derived from the full-length, rat GR expression vector (RGR), which was inhibited by VP22GR in COS 7 cells to the same extent as the human GR (data not shown). The TAT3-luc reporter was used to analyse the function of the two deletants because MMTV-luc was not regulated by either.

RGRN525 was more active than RGR 407C at $1 \mathrm{nM}$ dexamethasone, as expected, at a sub-saturating concentration of ligand (Fig. 3a). Expression of the VP22GR resulted in a dexamethasone-dependent inhibition of both RGRN525 and RGR407C activity (Fig. 3a).

In contrast to VP22GR, VP22GR(-LBD) had no dominant negative activity (Fig. 3b), and neither did a dimerisation-deficient variant (VP22 GRdim) (Fig. 3c).

\section{Response element specificity of VP22GR effects}

The VP22GR opposed hydrocortisone activation of the MMTV-luc reporter in mineralocorticoid receptor transfected cells (Fig. 4a), but did not antagonise the activity of the estrogen receptor on an ERE-luc construct (Fig. 4b). Interestingly inhibition of MR function was consistently greater at higher ligand concentrations, an effect also seen with inhibition of GR transactivation (Figs 1a, 2a, 2d, 3).

Figure 4 DNA template specificity for dominant negative action of VP22GR. (a) COS 7 cells were co-transfected with $3 \mu \mathrm{g}$ MMTV-luc, $1 \mu \mathrm{g} C M V-M R$ (MR), $1 \mu \mathrm{g} C M V-\beta G a l$, and with either $1 \mu \mathrm{g}$ VP22 (VP22) or $1 \mu \mathrm{g}$ VP22GR (VP22GR). Cells were divided and treated with the indicated concentrations of hydrocortisone (Hc) overnight before harvest as previously described. Results are expressed as fold induction of corrected relative light units \pm standard deviation. ${ }^{*} P<0 \cdot 05$ compared with VP22 transfected control cells at the same concentration of ligand. (b) COS 7 cells were co-transfected with $3 \mu \mathrm{g}$ ERE-luc, $1 \mu \mathrm{g}$ CMV-ER (ER), $1 \mu \mathrm{g}$ CMV- $\beta$ Gal, and with either $1 \mu \mathrm{g}$ VP22 (VP22), or $1 \mu \mathrm{g}$ VP22GR (VP22GR). Cells were divided and treated with the indicated concentrations of estradiol (E2) overnight before harvest as previously described. Results are expressed as fold induction of corrected relative light units \pm standard deviation. VP22GR did not differ significantly from VP22. A representative experiment, performed in triplicate and repeated on three occasions.
Activity of VP22GR on transrepression

GR inhibited expression of an NFKB regulated reporter gene (NRE-luc) in RelA transfected COS 7 cells (Fig. 5a). Surprisingly, the VP22GR also inhibited the activity of the NRE-luc. The maximal inhibition seen with the VP22GR was equivalent to that seen with the wtGR (Fig. 5a), but significant repression was seen at $1 \mathrm{nM}$ dexamethasone for the VP22 GR, and at $0 \cdot 1 \mathrm{nM}$

(a)

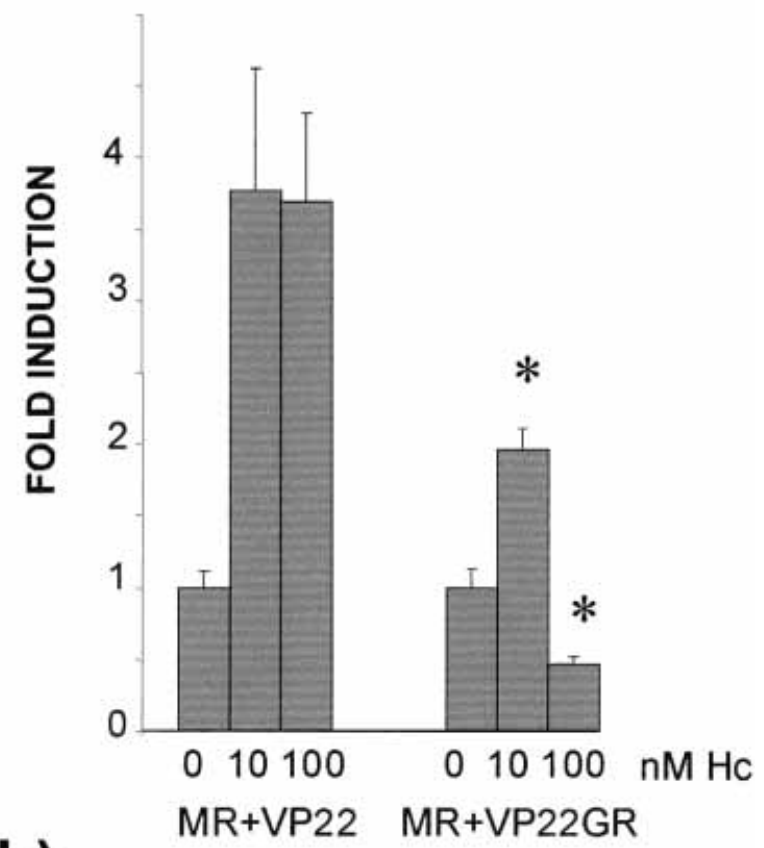

(b)

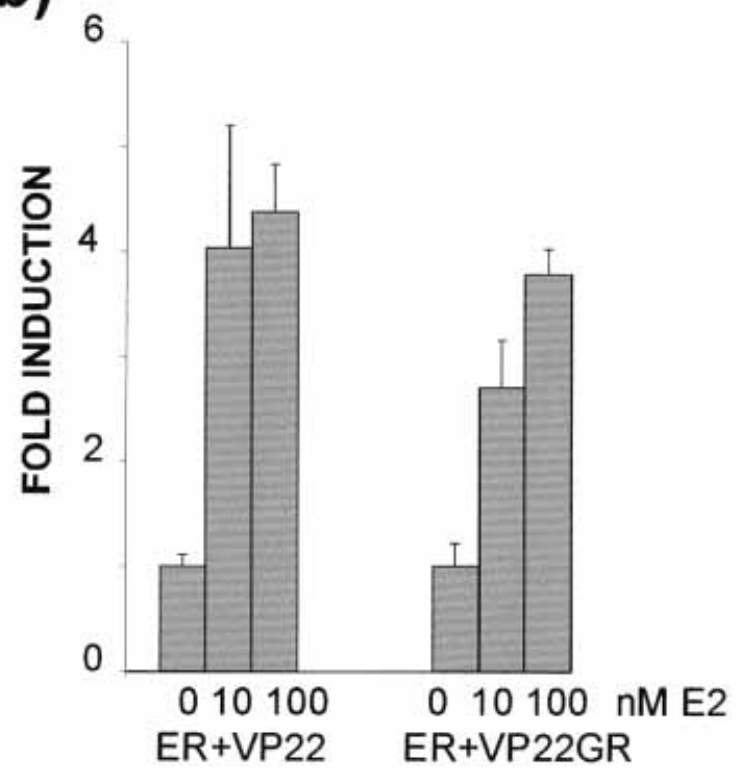

www.endocrinology.org 

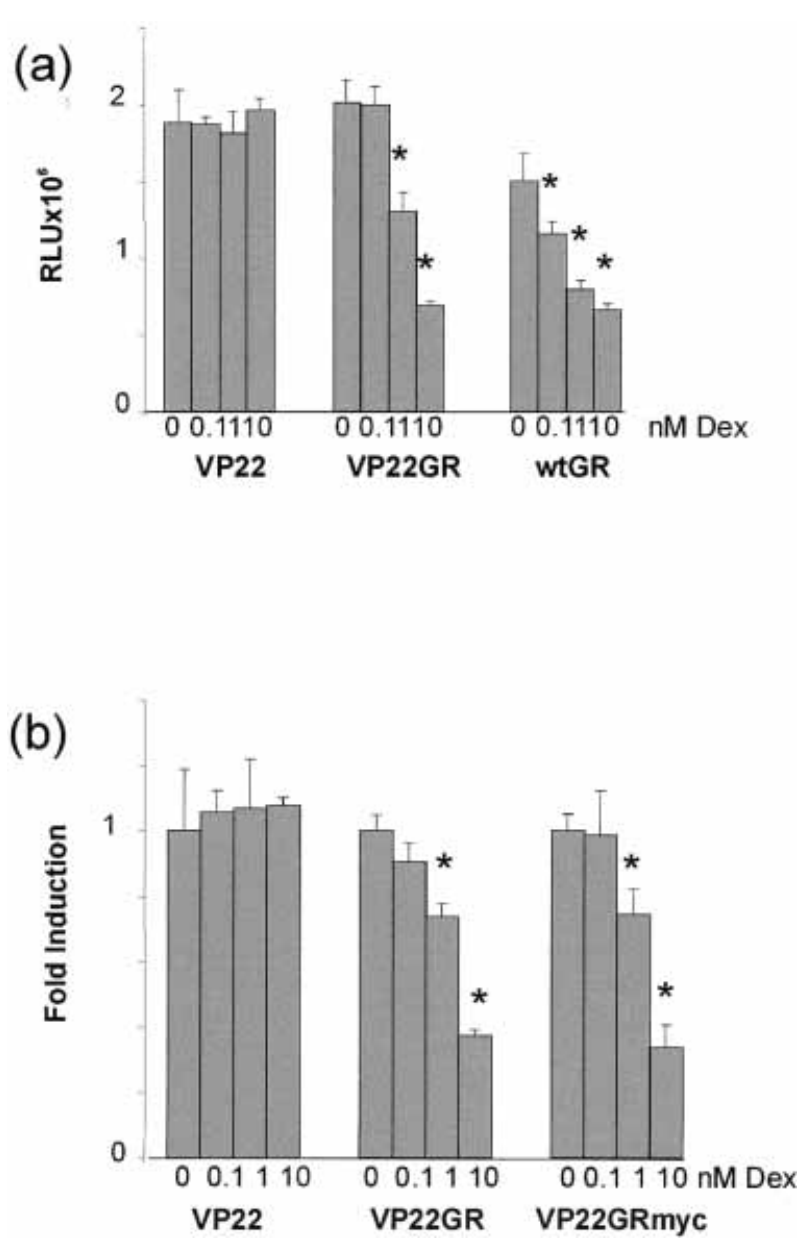

Figure 5 VP22GR inhibits NFKB RelA function. (a) COS 7 cells were co-transfected with $3 \mu \mathrm{g}$ NRE-luc, $1 \mu \mathrm{g}$ CMV- $\beta$ Gal, $200 \mathrm{ng}$ RelA expression vector, and with $1 \mu \mathrm{g}$ VP22, $1 \mu \mathrm{g}$ VP22GR, or $1 \mu \mathrm{g}$ wtGR. Cells were divided and incubated with the indicated concentrations of dexamethasone (Dex) for $16 \mathrm{~h}$ before harvest, as described. Results are expressed as mean corrected relative light units $(\mathrm{RLU}) \pm$ standard deviation. ${ }^{*} P<0 \cdot 05$ compared with vehicle treated cells from the same transfection. (b) The activity of VP22 was compared with VP22GR and VP22 GRmyc in the same assay as (a). Results are expressed as fold induction of corrected $\mathrm{RLU}$, means \pm standard deviation. ${ }^{*} P<0.05$ compared with vehicle treated control from the same transfection. A representative experiment, performed in triplicate and repeated on seven occasions.

dexamethasone for the GR (Fig. 5a,b). We also examined the function of a VP22 GRmyc, which differed in having a C terminal epitope tag. This did not alter its anti-RelA activity (Fig. 5b) or its dominant negative activity on GR transactivation (data not shown).

VP22GR not only conferred glucocorticoid regulation of RelA function on GR-deficient cells (Fig. 5), but it also enhanced glucocorticoid repression of RelA function in cells with endogenous GR function, A549 (Fig. 6). Exogenous GR allowed significant repression at $1 \mathrm{nM}$ dexamethasone, but the VP22GR required $10 \mathrm{nM}$ dexamethasone before significant repression was seen. The inhibition with dexamethasone in vector-transfected cells did not reach significance under these conditions. There was no ligand-independent reduction in NRE-luc activity.

\section{VP22GR intracellular localisation}

Addition of the $\mathrm{C}$ terminal myc epitope facilitated detection of the VP22GR fusion protein, allowed discrimination between it and GR, and did not alter protein function for dominant negative or transrepressive activity. Western blotting revealed a major protein species at $120 \mathrm{kDa}$, the predicted mass of the VP22GR fusion (data not shown). Immunocytochemistry showed that the VP22GR was located within the cytoplasm of transfected COS 7 cells (Fig. 7a,c). Dexamethasone induced almost complete nuclear localisation of the VP22 GRmyc (Fig. 7b,d).

To compare the intracellular distribution of VP22GR with wild-type GR we used an $\mathrm{N}$ terminal green fluorescent protein (GFP) fused to the murine wtGR. This molecule has previously been shown to retain liganddependent transactivation function, and to undergo appropriate nuclear translocation following ligand exposure. Both the VP22 GRmyc (Fig. 8a) and GFPGR (Fig. 8c) show cytoplasmic distribution, and both undergo nuclear translocation with the characteristic nucleolar exclusion pattern. The pattern of staining is indistinguishable between the cells expressing the GFPGR and those expressing the VP22 GRmyc (Fig. 8b,d and e). Some GFPGR transfected cells showed perinuclear accumulation of VP22 GRmyc (Fig. 8d), suggesting that cell-to-cell transfer of VP22GR had occurred. COS 7 cells were also co-transfected with VP22 GR myc and GFPGR. The two proteins showed complete overlap of nuclear distribution after dexamethasone (Fig. 8 (f)).

\section{Discussion}

The therapeutically useful, anti-inflammatory actions of glucocorticoids result from inhibition of other transcription factor function, especially NFKB (Cato \& Wade 1996, Heck et al. 1997). Problems with glucocorticoid therapy include an indiscriminate range of actions, and acquired glucocorticoid resistance. If the glucocorticoid sensitivity within a focus of inflammation could be enhanced then low, 'safe', doses of glucocorticoid may suffice as effective therapy.

For the glucocorticoid receptor, an intracellular protein, to be useful it would need to be expressed and active in the majority of cells in its targeted area. For this reason we evaluated VP22 as an intercellular transporter for GR protein. Previous work using other VP22 fusions had shown retained cargo protein function with either GFP 


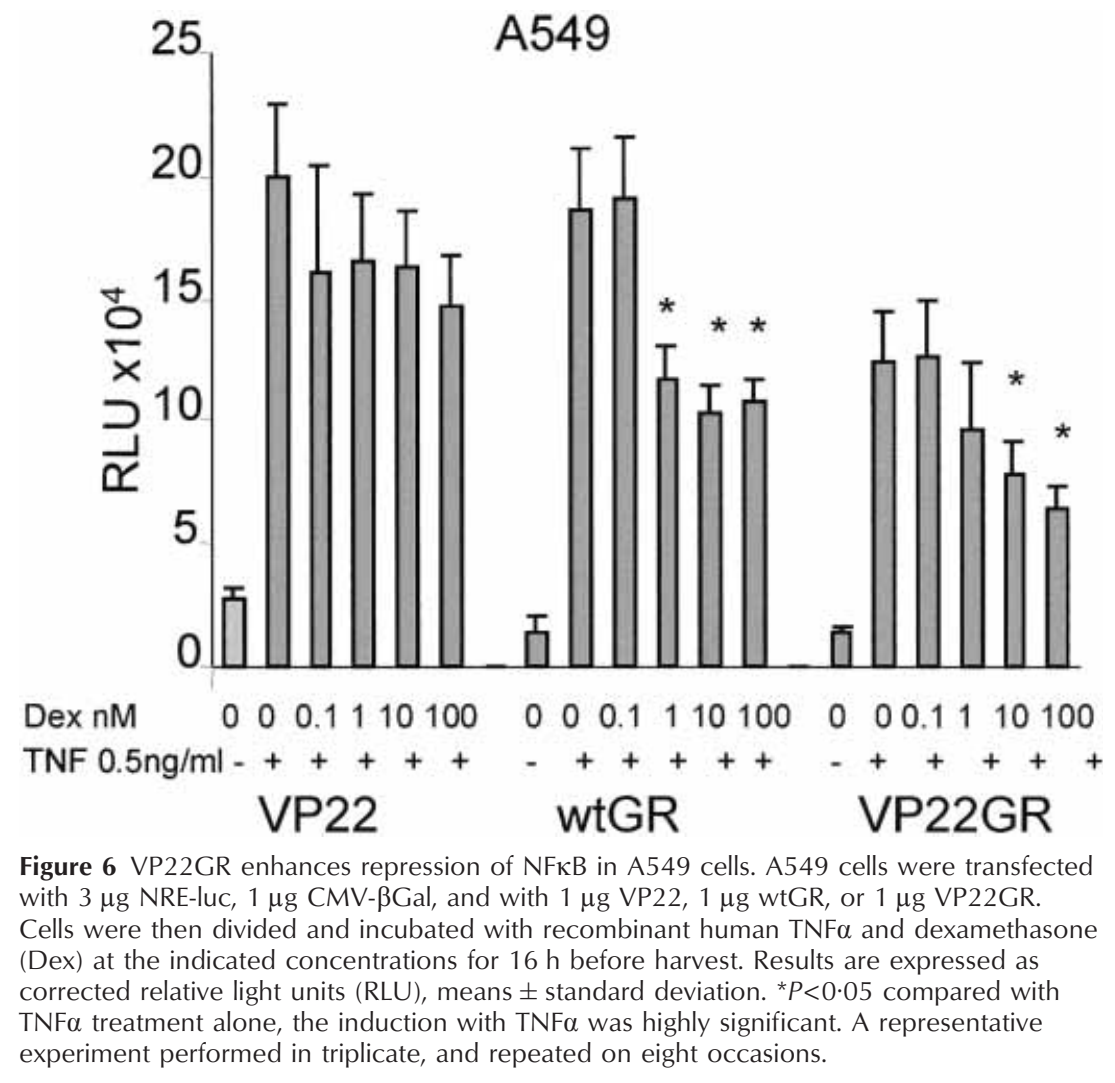

(Elliott \& O'Hare 1999) or p53 (Phelan et al. 1998), supporting the idea that GR function might be retained in a VP22GR fusion protein. Furthermore, the VP22 appeared to direct nuclear localisation (Elliott \& O'Hare 1997, 1999), and thereby might alter GR function by targeting unliganded GR to the nucleus.

We initially made an almost full-length GR fusion, deleting the first 41 amino acids which do not contribute significantly to protein function (Hollenberg \& Evans 1988, Scheinman et al. 1995b, Iniguez et al. 1997). Despite retaining both AF-1 and AF-2, the resulting VP22GR was unable to transactivate simple reporter genes. Not only did VP22GR lack the expected ligand-dependent transactivation of MMTV-luc and TAT3-luc, but surprisingly it exhibited dominant negative activity on endogenous GR in HeLa, A549, and CEM C7A cells. VP22GR also inhibited transfected wild-type GR in COS 7 cells (Fig. 2). The GR $N$ terminal has been analysed by deletion and alanine scanning approaches, and more recently by mutagenesis studies in yeast (Hollenberg et al. 1987, Hollenberg \& Evans 1988, Iniguez et al. 1997, Iniguez \& Pearce 2000). The domain from amino acid 77 to 262 contains a major transactivation function, a c-jun interacting function, and a synergy limiting activity (Iniguez et al. 1997, Hittelman et al. 1999, Iniguez \& Pearce 2000). The N terminal activation domain may interact with the $\mathrm{C}$ terminal activation domain to synergistically enhance transcription on some DNA templates (Hollenberg \& Evans 1988, Hittelman et al. 1999). However, no function has been ascribed to the $\mathrm{N}$ terminal 42 amino acids, and therefore it is unlikely that deletion of these residues, in isolation, would be sufficient to abolish transactivation activity of the GR. Previously, N terminal GR fusion proteins, e.g. with GFP $(27 \mathrm{kDa})$, had been shown to retain transactivation potential (Htun et al. 1996, Galigniana et al. 1999). Furthermore, fusion of GFP had been performed not only to the extreme $\mathrm{N}$ terminus of GR, but also up to amino acid 132 without abrogating transactivation activity (Ogawa et al. 1995). This suggests that $\mathrm{N}$ terminal fusions up to amino acid 132 are not sufficient to abolish the transactivation function of the GR.

The VP22GR, or a variant with a $\mathrm{C}$ terminal myc epitope tag, was effective at inhibiting transactivation both by a C terminal truncated, constitutively active GR (RGRN525) and also by an $\mathrm{N}$ terminal deleted GR (RGR407C). Dominant negative activity could be abolished by disrupting either the $\mathrm{C}$ terminal of the VP22GR (VP22GR(-LBD)), or dimerisation function (VP22 GR dim). As the dominant negative function of the VP22GR appeared to be dependent on DNA binding, we examined the specificity of DNA response element sequence. The MR shares both DNA element sequence 


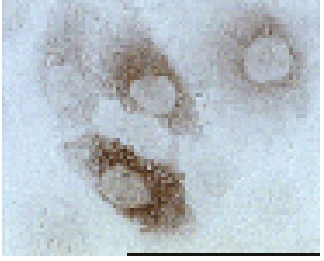

(a) NoDex

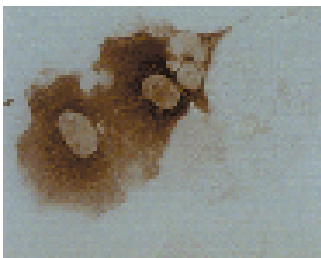

(c) NoDex

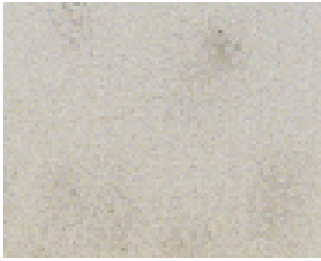

(e) NoDex

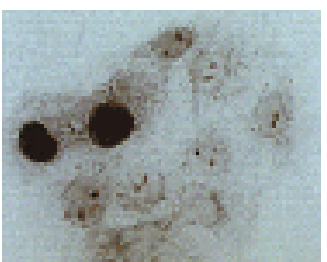

(b) PlusDex

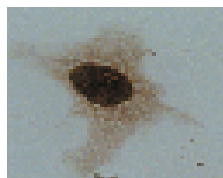

(d) PlusDex

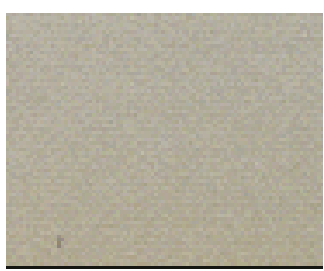

(f) NoDex
Figure 7 Expression and localisation of VP22 GRmyc fusion protein. COS 7 cells were transfected with the VP22 GRmyc expression vector (a), (b), (c), (d), or empty expression vector VP22 (e), (f), then divided. Protein was detected with anti-GR antibody (P20) in (a), (b) and (e), and with anti-myc antibody in (c), (d) and (f). Cells in (b) and (d) were treated with $100 \mathrm{nM}$ dexamethasone (Dex) for $16 \mathrm{~h}$, the others were not.

and ligand with the GR; it also has a higher affinity for hydrocortisone. VP22GR inhibited transactivation by the MR, but did not significantly inhibit the activity of the ER. This suggests that the VP22GR is inhibiting GR function specifically, and that it does so by acting through its specific DNA response element. Furthermore, such inhibition may require either homodimerisation of VP22GR or heterodimerisation between the VP22GR and GR.

As the VP22GR molecule had such an unexpected profile of activity on transactivation end-points, GR inhibition of NFKB activity was measured. We used the well-characterised NRE-luc reporter gene driven by overexpressed p65 (Ray et al. 1999). Surprisingly, and in contrast to the transactivation results, the VP22GR and the VP22 GRmyc were just as effective at inhibiting the p65 function as the wild-type GR. However, there was a consistent right-shift in the dose-response of this effect with both the VP22GR and the VP22 GRmyc compared with the wtGR. The VP22GR fusion proteins did not

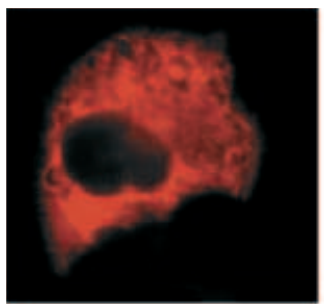

(a) NoDex

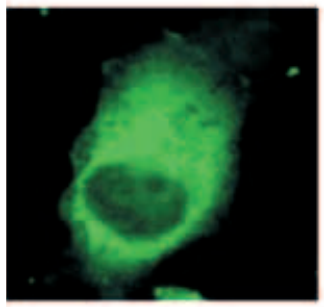

(c) NoDex

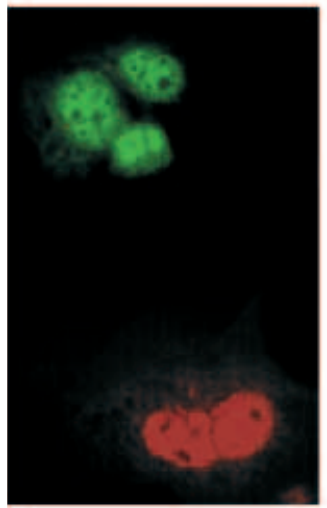

(e) PlusDex

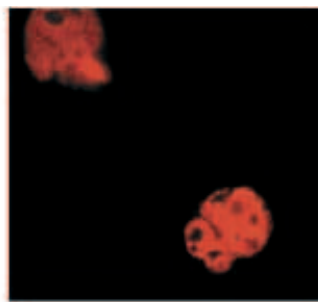

(b) PlusDex

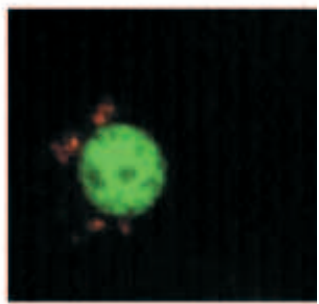

(d) PlusDex

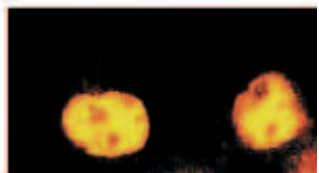

(f) PlusDex
Figure 8 Intracellular distribution of GFPGR and VP22 GRmyc. COS 7 cells were transfected with either GFPGR or VP22 GRmyc, then divided, mixed, and treated with or without $100 \mathrm{nM}$ dexamethasone (Dex) for $16 \mathrm{~h}$. VP22 GRmyc was detected with anti-myc and Texas Red-conjugated second antibody, and the GFPGR was detected by its intrinsic fluorescence. Cells in (a) and (b) were viewed under the red filter, with and without $100 \mathrm{nM}$ dexamethasone as indicated. Cells in (c) and (d) were viewed under both the red and green filters and the images overlaid, again with or without dexamethasone. (e) Cells were imaged after $100 \mathrm{nM}$ dexamethasone and red and green images overlaid. (f) COS 7 cells were co-transfected with $2.5 \mu \mathrm{g}$ GFPGR and $2.5 \mu \mathrm{g}$ VP22 GRmyc, and incubated with dexamethasone. VP22 GRmyc was detected using the anti-myc antibody and Texas Red-conjugated second antibody as described in Materials and Methods, and the figure is an overlaid image.

repress RelA function at less than $1 \mathrm{nM}$ dexamethasone, in contrast to wild-type GR. We also examined VP22GR function in a cell line expressing endogenous GR, A549. In these cells the NRE reporter gene was activated by 
tumour necrosis factor- $\alpha$ (TNF $\alpha$ ). Both wild-type GR and VP22GR were capable of significantly repressing the NRE reporter gene.

Previous work has shown that mutation to the DNA binding domain of the GR, or to the ligand binding domain can result in impaired, but not abolished transactivation (Heck et al. 1997, Ray et al. 1999). However, no changes to the $\mathrm{N}$ terminal of the GR have been reported to result in such dissociation of transrepression from transactivation, and certainly no changes have been reported to confer dominant negative activity on transactivation.

The GR is known to interact with a wide range of proteins. To transactivate target genes, co-activator molecules are recruited to the DNA bound GR, and these serve to 'bridge' a signal to the basal transcriptional machinery (Collingwood et al. 1999, McKenna et al. 1999). The progesterone receptor (PR) and estrogen receptor (ER) are also capable of recruiting co-repressor proteins when activated by antagonist ligands and thereby inhibiting target gene expression (Laherty et al. 1998, Lavinsky et al. 1998). The GR is proposed to recruit a co-repressor when 'tethered' to an NFKB response element by RelA, and this is thought to be the mechanism of GR repression of NFKB activity (Nissen \& Yamamoto 2000).

It is likely that the VP22 portion of the VP22GR is responsible for modifying the activity of the GR, generating a dominant negative molecule for transactivation. However, the different mode of GR action to oppose p65 is not disturbed by the presence of the $\mathrm{N}$ terminal VP22. Either competition for DNA binding, and failure to recruit co-activators, or recruitment of additional factors to the VP22 portion of the VP22GR fusion and so disruption of normal complex formation would explain the dominant negative action of VP22GR on GR transactivation. The preservation of transrepressing activity seen with VP22GR suggests that this activity requires a substantially different pattern of protein-protein interaction, and that this is not disturbed by the presence of the VP22 sequence, nor any accessory proteins recruited by it. This further underlines the separation of the two pathways, and is the first example of an $\mathrm{N}$ terminal GR modification capable of dissociating them so completely. The minor right-shift in dose-response consistently seen with VP22GR suggests a minor reduction in ligand binding affinity, possibly by altering chaparone protein interactions in the cytosol.

As VP22 had variously been described to target cargo proteins to the cytoplasm or nucleus of transfected cells, and also appeared to interact directly with the tubulin architecture of the cells (Elliott \& O'Hare 1997), we wished to determine where the VP22GR was within the cell, and how it responded to ligand treatment. In the unliganded state the VP22 GRmyc was found exclusively in the cytoplasm where its distribution was reticular. Following ligand addition, the molecule underwent almost complete nuclear translocation, to result in a homogeneous distribution with characteristic lacunae, probably nucleoli, as previously described for the GR (Htun et al. 1996). After dexamethasone treatment, the pattern of intranuclear distribution was identical for both the GFPGR and the VP22 GRmyc.

In summary, we describe the impact of $\mathrm{N}$ terminal fusion of the GR with the herpes viral protein, VP22. This fusion results in a protein with a novel spectrum of ligand-dependent activity. The striking finding that the fusion retained the therapeutically useful anti NFKB activity while acquiring a powerful, ligand-dependent dominant negative action on GR mediated transactivation suggests that $\mathrm{N}$ terminal modification of the GR may be a novel manner in which to alter the specificity of GR actions. Previous attempts to focus GR actions have resulted in selective loss of transactivation, to a greater or lesser extent (Heck et al. 1997, Reichardt et al. 1998, Ray et al. 1999). As yet, no modification has resulted in such an extreme dissociation of the two modes of GR action as this $\mathrm{N}$ terminal fusion. This suggests a means to alter GR function by generating $\mathrm{N}$ terminal fusion proteins. Moreover, such 'designer' proteins may find a use in gene therapy applications.

\section{Acknowledgements}

We are grateful to Dr Daniella Riccardi and Mr John Denton for help with microscopy, Professor Keith Yamamoto and Dr Jorge Iniguez-Lluhi, and Dr Peter Herrlich for the gift of plasmids, Dr Paul Housley for the gift of the GFPGR, Professor A M Heagerty for his support during this project, Professors P Lowenstein and M Castro for helpful discussions and Mr Daniel Stone for technical advice.

D W R was funded by a Glaxo-Wellcome Fellowship. This work was supported by grants from the Royal Society, The University of Manchester Research Support Fund and by Central Manchester Healthcare Trust Research and Development.

\section{References}

Caldenhoven E, Liden J, Wissink S, Van de Stolpe A, Raaijmakers J, Koenderman L, Okret S, Gustafsson JA \& Van der Saag PT 1995 Negative cross-talk between RelA and the glucocorticoid receptor: a possible mechanism for the anti-inflammatory action of glucocorticoids. Molecular Endocrinology 9 401-412.

Cato AC \& Wade E 1996 Molecular mechanisms of antiinflammatory action of glucocorticoids. Bioessays 18 371-378.

Collingwood TN, Urnov FD \& Wolffe AP 1999 Nuclear receptors: coactivators, corepressors and chromatin remodeling in the control of transcription. Journal of Molecular Endocrinology 23 255-275.

Elliott G \& O'Hare P 1997 Intercellular trafficking and protein delivery by a herpes virus structural protein. Cell 88 223-233.

Elliott G \& O'Hare P 1999 Intercellular trafficking of VP22-GFP fusion proteins. Gene Therapy 6 149-151. 
Fang B, Xu B, Koch P \& Roth JA 1998 Intercellular trafficking of VP22-GFP fusion proteins is not observed in cultured mammalian cells. Gene Therapy 5 1420-1424.

Galigniana MD, Scruggs JL, Herrington J, Welsh MJ, Carter SC, Housley PR \& Pratt WB 1998 Heat shock protein 90-dependent (geldanamycin-inhibited) movement of the glucocorticoid receptor through the cytoplasm to the nucleus requires intact cytoskeleton. Molecular Endocrinology 12 1903-1913.

Galigniana MD, Housley PR, DeFranco DB \& Pratt WB 1999 Inhibition of glucocorticoid receptor nucleocytoplasmic shuttling by okadaic acid requires intact cytoskeleton. Journal of Biological Chemistry 274 16222-16227.

Godowski PJ, Picard D \& Yamamoto KR 1988 Signal transduction and transcriptional regulation by glucocorticoid receptor-LexA fusion proteins. Science 241 812-816.

Heck S, Kullmann M, Gast A, Ponta H, Rahmsdorf HJ, Herrlich P \& Cato AC 1994 A distinct modulating domain in glucocorticoid receptor monomers in the repression of activity of the transcription factor AP-1. EMBO Journal 13 4087-4095.

Heck S, Bender K, Kullmann M, Gottlicher M, Herrlich P \& Cato AC 1997 I kappaB alpha-independent downregulation of NF-kappaB activity by glucocorticoid receptor. EMBO Journal 16 4698-4707.

Hittelman AB, Burakov D, Iniguez LJ, Freedman LP \& Garabedian MJ 1999 Differential regulation of glucocorticoid receptor transcriptional activation via AF-1-associated proteins. EMBO Journal 18 5380-5388.

Hollenberg SM \& Evans RM 1988 Multiple and cooperative trans-activation domains of the human glucocorticoid receptor. Cell 55 899-906.

Hollenberg SM, Giguere V, Segui P \& Evans RM 1987 Colocalization of DNA-binding and transcriptional activation functions in the human glucocorticoid receptor. Cell 49 39-46.

Hong H, Kohli K, Garabedian MJ \& Stallcup MR 1997 GRIP1, a transcriptional coactivator for the AF-2 transactivation domain of steroid, thyroid, retinoid and vitamin D receptors. Molecular and Cellular Biology 17 2735-2744.

Horwitz KB, Jackson TA, Bain DL, Richer JK, Takimoto GS \& Tung L 1996 Nuclear receptor coactivators and corepressors. Molecular Endocrinology 10 1167-1177.

Htun H, Barsony J, Renyi I, Gould DL \& Hager GL 1996 Visualization of glucocorticoid receptor translocation and intranuclear organization in living cells with a green fluorescent protein chimera. PNAS 93 4845-4850.

Iniguez LJ \& Pearce D 2000 A common motif within the negative regulatory regions of multiple factors inhibits their transcriptional synergy. Molecular and Cellular Biology 20 6040-6050.

Iniguez LJ, Lou DY \& Yamamoto KR 1997 Three amino acid substitutions selectively disrupt the activation but not the repression function of the glucocorticoid receptor $\mathrm{N}$ terminus. Journal of Biological Chemistry 272 4149-4156.

Jonat C, Rahmsdorf HJ, Park KK, Cato AC, Gebel S, Ponta H \& Herrlich P 1990 Antitumor promotion and anti-inflammation: down-modulation of AP-1 (Fos/Jun) activity by glucocorticoid hormone. Cell 62 1189-1204.

Koelle DM, Frank JM, Johnson ML \& Kwok WW 1998 Recognition of herpes simplex virus type 2 tegument proteins by CD4 T cells infiltrating human genital herpes lesions. Journal of Virology 72 7476-7483.

Konig H, Ponta H, Rahmsdorf HJ \& Herrlich P 1992 Interference between pathway-specific transcription factors: glucocorticoids antagonize phorbol ester-induced AP-1 activity without altering AP-1 site occupation in vivo. EMBO Journal 11 2241-2246.

Laherty CD, Billin AN, Lavinsky RM, Yochum GS, Bush AC, Sun JM, Mullen Davie JR, Rose DW, Glass CK, Rosenfeld MG, Ayer DE \& Eisenman RN 1998 SAP30, a component of the mSin3 corepressor complex involved in N-CoR-mediated repression by specific transcription factors. Molecular Cell 2 33-42.
Lavinsky RM, Jepsen K, Heinzel T, Torchia J, Mullen TM, Schiff R, Del Ricote M, Ngo S, Gemsch J, Hilsenbeck SG, Osborne CK, Glass Rosenfeld MG \& Rose DW 1998 Diverse signaling pathways modulate nuclear receptor recruitment of N-CoR and SMRT complexes. PNAS 95 2920-2925.

McKenna NJ, Lanz RB \& O’Malley BW 1999 Nuclear receptor coregulators: cellular and molecular biology. Endocrine Reviews 20 321-344.

Mathieu M, Gougat C, Jaffuel D, Danielsen M, Godard P, Bousquet J \& Demoly P 1999 The glucocorticoid receptor gene as a candidate for gene therapy in asthma. Gene Therapy 6 245-252.

Miner JN \& Yamamoto KR 1991 Regulatory crosstalk at composite response elements. Trends in Biochemical Sciences 16 423-426.

Nissen RM \& Yamamoto KR 2000 The glucocorticoid receptor inhibits NFkappaB by interfering with serine-2 phosphorylation of the RNA polymerase II carboxy-terminal domain. Genes and Development 14 2314-2329.

Ogawa H, Inouye S, Tsuji FI, Yasuda K \& Umesono K 1995 Localization, trafficking \& temperature-dependence of the Aequorea green fluorescent protein in cultured vertebrate cells. PNAS $\mathbf{9 2}$ 11899-11903.

Phelan A, Elliott G \& O'Hare P 1998 Intercellular delivery of functional p53 by the herpes virus protein VP22 [see comments]. Nature Biotechnology 16 440-443.

Ray A \& Prefontaine KE 1994 Physical association and functional antagonism between the p65 subunit of transcription factor NF-kappa B and the glucocorticoid receptor. PNAS 91 752-756.

Ray DW, Davis JR, White A \& Clark AJ 1996a Glucocorticoid receptor structure and function in glucocorticoid-resistant small cell lung carcinoma cells. Cancer Research 56 3276-3280.

Ray DW, Ren SG \& Melmed S 19966 Leukemia inhibitory factor (LIF) stimulates proopiomelanocortin (POMC) expression in a corticotroph cell line. Role of STAT pathway. Journal of Clinical Investigation 97 1852-1859.

Ray DW, Suen C-S, Brass A, Soden J \& White A 1999 Structure/function of the human glucocorticoid receptor: tyrosine 735 is important for transactivation. Molecular Endocrinology 13 1855-1864.

Reichardt HM, Kaestner KH, Tuckermann J, Kretz O, Wessely O, Bock R, Gass P, Schmid W, Herrlich P, Angel P \& Schutz G 1998 DNA binding of the glucocorticoid receptor is not essential for survival [see comments]. Cell 93 531-541.

Scheinman RI, Cogswell PC, Lofquist AK \& Baldwin AS J 1995a Role of transcriptional activation of I kappa B alpha in mediation of immunosuppression by glucocorticoids [see comments]. Science $\mathbf{2 7 0}$ 283-286.

Scheinman RI, Gualberto A, Jewell CM, Cidlowski JA \& Baldwin AS J 1995b Characterization of mechanisms involved in transrepression of NF-kappa B by activated glucocorticoid receptors. Molecular and Cellular Biology 15 943-953.

Schule R \& Evans RM 1991 Functional antagonism between oncoprotein c-Jun and steroid hormone receptors. Cold Spring Harbor Symposiums in Quantitative Biology 56 119-127.

Vanderbilt JN, Miesfeld R, Maler BA \& Yamamoto KR 1987 Intracellular receptor concentration limits glucocorticoid-dependent enhancer activity. Molecular Endocrinology 1 68-74.

Wade EJ, Heck S \& Cato AC 1995 Glucocorticoid receptor-activator protein-I interactions in drug design. Biochemical Society Transactions 23 946-952.

Warnmark A, Gustafsson JA \& Wright AP 2000 Architectural principles for the structure and function of the glucocorticoid receptor tau 1 core activation domain. Journal of Biological Chemistry 275 15014-15018.

Received 14 September 2001

Accepted 31 October 2001 